УДК 004.738:006.354

\title{
ТИПОВЫЕ МОДЕЛИ ЦИФРОВЫХ ДВОЙНИКОВ УМНОГО ПРОИЗВОДСТВА НА ОСНОВЕ ДОМЕНОВ И СУЩНОСТЕЙ
}

\author{
Андрианова Людмила Прокопьевна \\ д-р техн. наук, профессор \\ Голубев Дэнис Михайлович \\ студент
}

Уфимский государственный нефтяной технический университет

Аннотация: В статье приведены результаты анализа структурированного подхода к построению типовых моделей цифровых двойников умного производства. Рассмотрены подходы к построению моделей для представления типовой архитектуры цифровых двойников производства как виртуального представления элементов производственного процесса: персонал, оборудование, процессы обработки материалов, предприятия и продукты. Приведены структуры моделей цифровых двойников производства на основе доменов и сущностей. Результаты анализа систематизированы и представлены в табличном и графическом виде.

Ключевые слова: цифровой двойник производства, интернет вещей, типовая архитектура, модель цифрового двойника производства на основе доменов, модель цифрового двойника производства на основе сущностей, комбинированная модель цифрового двойника производства на основе доменов и сущностей.

\section{TYPICAL MODELS OF DIGITAL DOUBLES SMART PRODUCTION BASED ON DOMAINS AND ENTITIES}

\section{Andrianova Lyudmila Prokopyevna Golubev Denis Mikhailovich}

\begin{abstract}
The article presents the results of the analysis of the structured approach to the construction of standard models of digital counterparts of smart production. Approaches to the construction of models for the representation of a typical architecture of digital production doubles as a virtual representation of the elements of the production process are considered: personnel, equipment, material


handling processes, businesses, and products. The structures of models of digital production doubles based on domains and entities are presented. The results of the analysis are systematized and presented in tabular and graphical form.

Key words: digital production twin, internet of things, model architecture, domain-based digital production twin model, entity-based digital production twin model, combined domain-and entity-based digital production twin model.

Структурированный подход к построению типовых моделей и типовой архитектуры цифрового двойника умного производства изложен в ПНСТ 430 [1] и ПНСТ 431 [2]. Создание типовой архитектуры цифрового двойника производства, требования к типовой модели цифрового двойника производства, и архитектурным представлениям (функциональное и сетевое) поясняются с помощью рисунка 1.

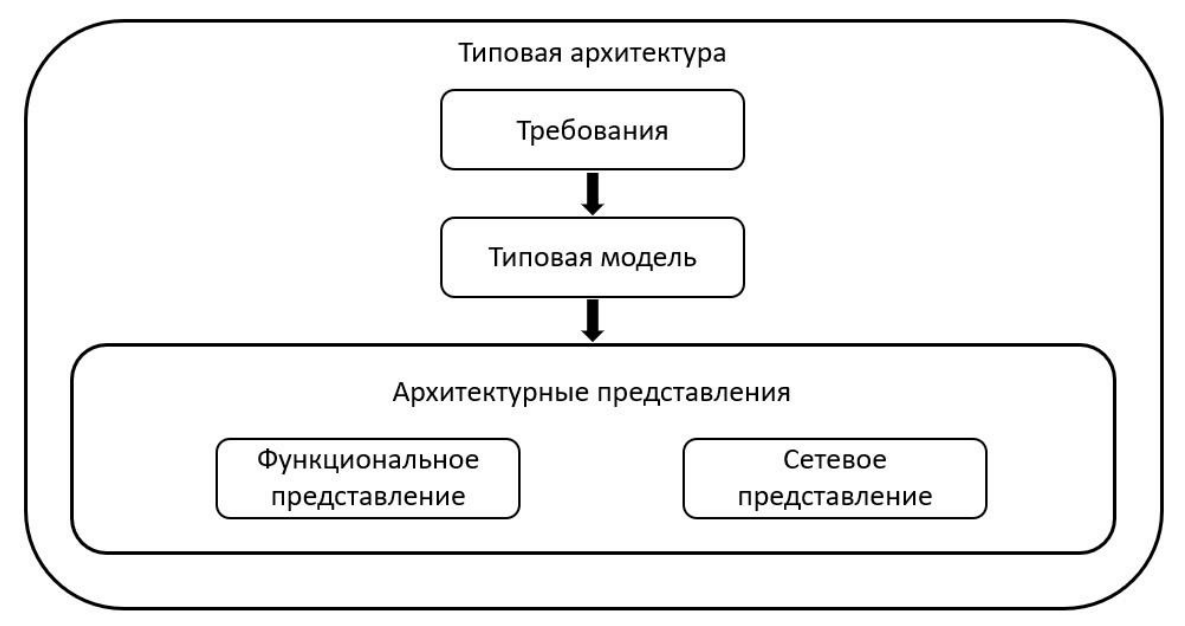

Рис. 1. Создание типовой архитектуры цифрового двойника

Для сбора и управления данными, а также в качестве концептуальной основы цифрового двойника производства используется Интернет вещей (ИВ).

Типовая модель Интернета вещей, включая типовую модель на основе доменов и типовую модель на основе сущностей, определена в ПНСТ 420 [3].

В соответствии с ПНСТ 430 [2] домены структуры цифрового двойника производства подразделяют на четыре категории в соответствии с задачами и функциями, находящимися в зоне ответственности каждого домена (табл. 1). 
Таблица 1

Домены структуры цифрового двойника производства

\begin{tabular}{|c|c|}
\hline Категория домена & Задачи и функции \\
\hline $\begin{array}{l}\text { 1. Домен сбора } \\
\text { данных и } \\
\text { управления } \\
\text { устройствами } \\
\text { (DCDCD) }\end{array}$ & $\begin{array}{l}\text { DCDCD отслеживает и считывает условия PMD для сбора данных и } \\
\text { управления устройствами, такими как датчики, камеры, } \\
\text { исполнительные устройства и другие составные устройства. } \\
\text { DCDCD связывает наблюдаемые производственные элементы с } \\
\text { цифровыми сущностями и. наоборот для их синхронизации. } \\
\text { DCDCD может физически существовать в том же домене, что и } \\
\text { PMD, однако логически они разделены, например, устройство } \\
\text { управления станком в соответствии с пространственным / } \\
\text { логическим / функциональным разделением. }\end{array}$ \\
\hline $\begin{array}{l}\text { 2. Домен } \\
\text { представления } \\
\text { цифрового } \\
\text { двойника (DTRD) }\end{array}$ & $\begin{array}{l}\text { DTRD состоит из субдоменов (табл. 2) : } \\
\text { Субдомен эксплуатации и управления (OMSD), } \\
\text { Субдомен приложений и сервисов (ASSD) } \\
\text { Субдомен доступа к ресурсам и обмена данными (RAISD) }\end{array}$ \\
\hline $\begin{array}{l}\text { 3. Домен } \\
\text { пользователя (UD). }\end{array}$ & $\begin{array}{l}\text { В структуре цифрового двойника производства пользователями } \\
\text { могут быть человек, устройство или система, которая использует } \\
\text { приложения и сервисы, предоставляемые DTRD. Даже если } \\
\text { пользователем является человек, он должен взаимодействовать с } \\
\text { DTRD с помощью определенного устройства. } \\
\text { Пример UD - производственный участок конечного пользователя } \\
\text { приложений и сервисов цифрового двойника в соответствии с } \\
\text { Интернет вещей, цифровой двойник производства, структура } \\
\text { цифрового двойника производства, типовая архитектура } \\
\text { пространственным / логическим / функциональным разделением. }\end{array}$ \\
\hline $\begin{array}{l}\text { 4. Домен } \\
\text { физического } \\
\text { производства } \\
\text { (PMD) }\end{array}$ & $\begin{array}{l}\text { PMD состоит из физических производственных ресурсов: персонал, } \\
\text { оборудование и материалы. РМD является основной средой } \\
\text { эксплуатации структуры цифрового двойника производства, данные } \\
\text { об условиях которой должны считываться и отслеживаться для } \\
\text { сбора и управления данными, например, производственный участок } \\
\text { станка в соответствии с пространственным /логическим / } \\
\text { функциональным разделением. } \\
P M D \text { не входит в структуру цифрового двойника производства [2, } \\
\text { с.4 ] }\end{array}$ \\
\hline
\end{tabular}

В таблице 1 (поз. 2) показано, что домен представления цифрового двойника (DTRD) является доменом высокого уровня и состоит из трех субдоменов OMSD, ASSD RAISD, задачи и выполняемые функции которых приведены в таблице 2 в соответствии с [2, с. 5- 6]. 
Таблица 2

Субдомены домена представления цифрового двойника (DTRD)

\begin{tabular}{|c|c|}
\hline Категория субдомена & Задачи и функции \\
\hline $\begin{array}{l}\text { 1. Субдомен } \\
\text { эксплуатации и } \\
\text { управления (OMSD) }\end{array}$ & $\begin{array}{l}\text { OMSD отвечает за эксплуатацию и управление всего DTRD, } \\
\text { включая подготовку управление, отслеживание и } \\
\text { оптимизацию DTRD. BOMSD осуществляется цифровое } \\
\text { моделирование, представление и синхронизация } \\
\text { наблюдаемого производственного элемента. } \\
\text { Примером OMSD является производственный участок } \\
\text { сервера управления внедрением иифрового двойника } \\
\text { производства в соответствии с пространственным / } \\
\text { логическим / функииональным разделением. }\end{array}$ \\
\hline $\begin{array}{l}\text { 2. Субдомен } \\
\text { приложений и } \\
\text { сервисов (ASSD) }\end{array}$ & $\begin{array}{l}\text { Приложения и сервисы цифрового двойника производства, } \\
\text { такие как эмуляция, анализ и т. д., находятся в ASSD. } \\
\text { Сущности в ASSD взаимодействуют с сущностями в OMSD, } \\
\text { отвечающими за управление DTRD. Кроме того, сущности в } \\
\text { ASSD могут взаимодействовать с внешними сущностями } \\
\text { через RAISD, который управляет взаимодействием с } \\
\text { внешними сущностями, такими как одноранговый DTRD. } \\
\text { Примером ASSD является производственный участок } \\
\text { сервера эмулящии цифррового двойника в соответствии с } \\
\text { пространственнылм / логическим / функциональнымм } \\
\text { разделением. }\end{array}$ \\
\hline $\begin{array}{l}\text { 3. Субдомен доступа } \\
\text { к ресурсам и обмена } \\
\text { данными (RAISD) }\end{array}$ & $\begin{array}{l}\text { RAISD управляет доступом к сущностям структуры } \\
\text { цифрового двойника производства и взаимодействием с } \\
\text { внешними сущностями, такими как одноранговый DTRD, } \\
\text { обеспечивая их совместимость. } \\
\text { Примером RAISD является производственный участок } \\
\text { сервера аутентификаиии и авторизаџии в соответствии с } \\
\text { пространственным / логическим / функииональным } \\
\text { разделением. }\end{array}$ \\
\hline
\end{tabular}

Типовая модель структуры цифрового двойника производства на основе доменов показана на рисунке 2.

Типовая модель на основе доменов подходит для описания различных задач, которые должны быть выполнены на отдельных производственных участках с учетом логического, а иногда и физического разделения. В основном домены используют для разделения функций по зонам ответственности [2]. 


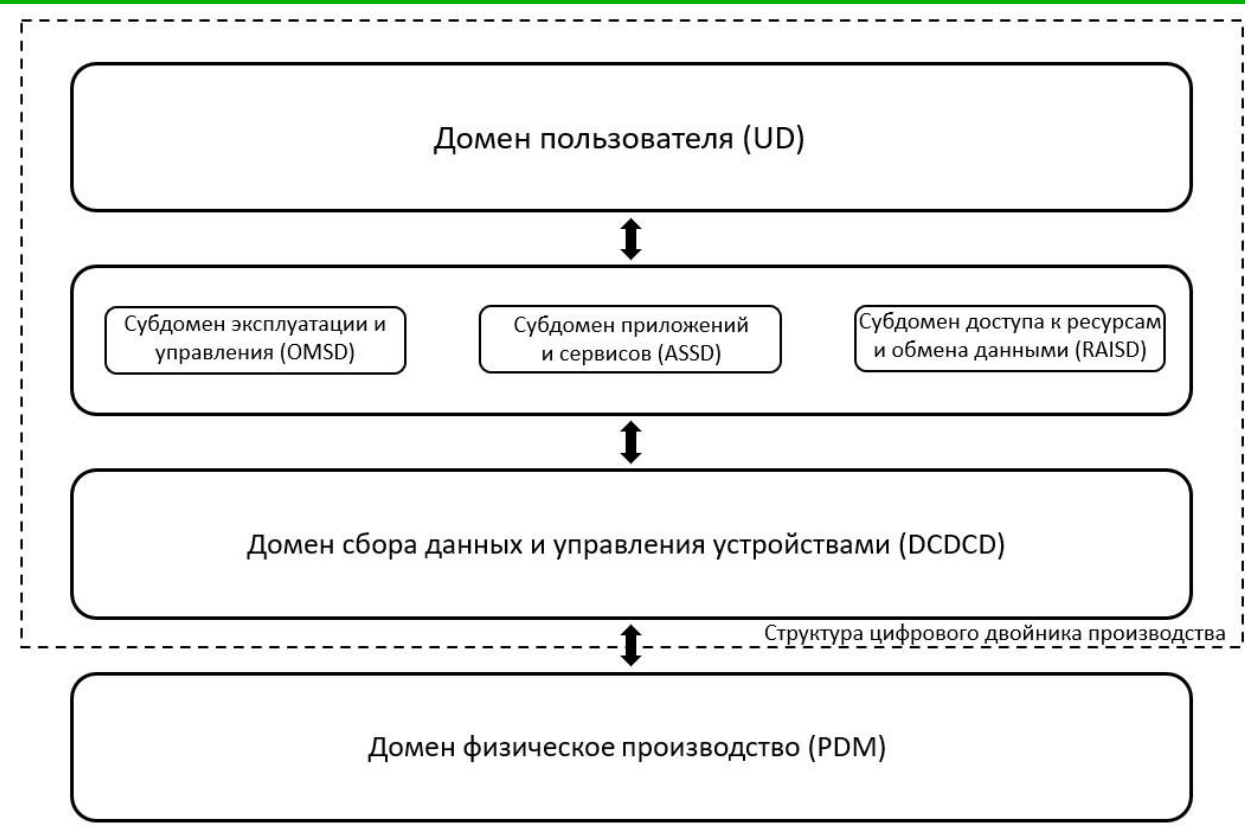

\section{Рис. 2. Типовая модель цифрового двойника производства на основе доменов}

Типовая модель цифрового двойника производства на основе сущностей приведена на рисунке 3 [2].
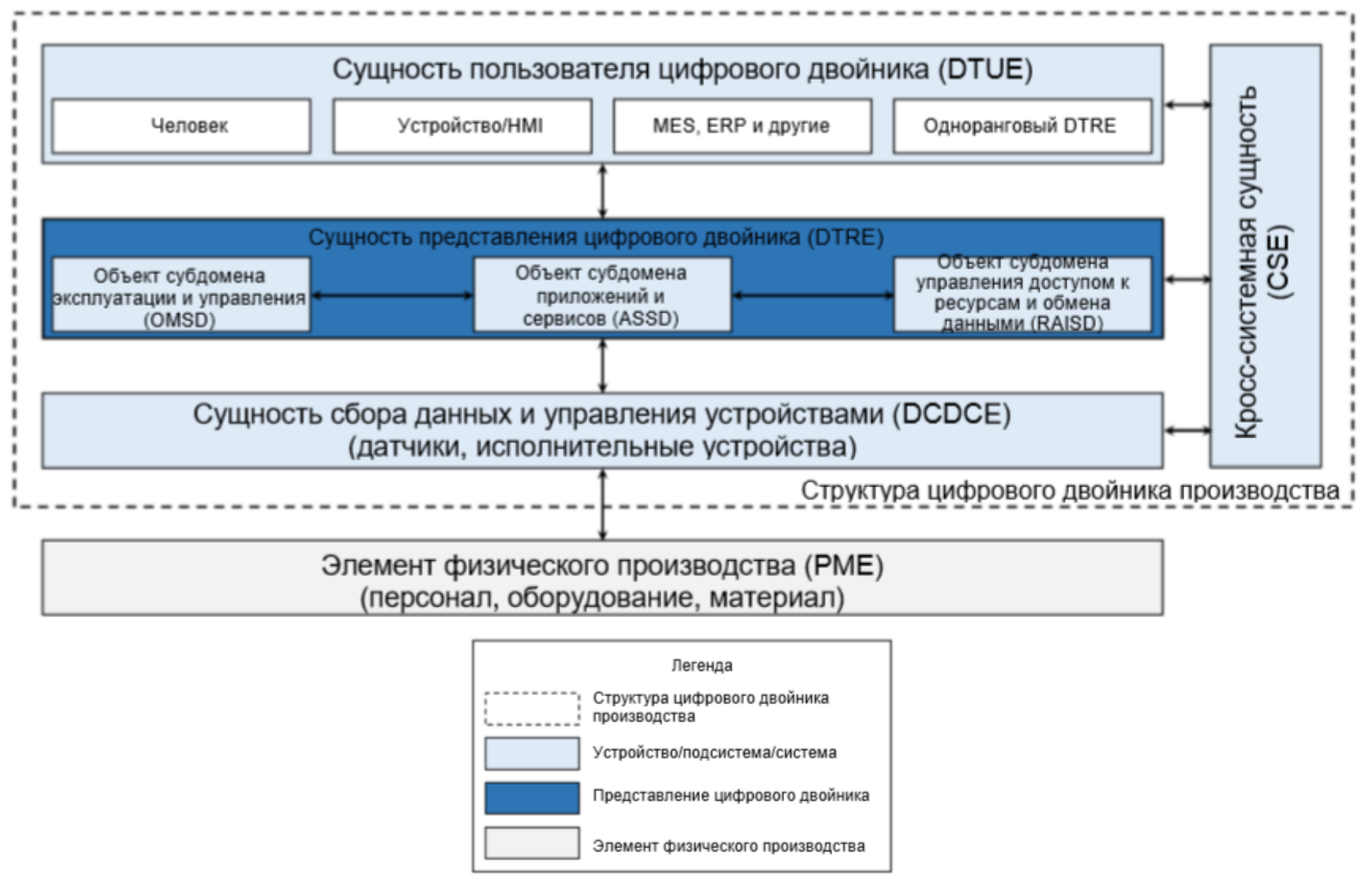

Рис. 3.Типовая модель цифрового двойника производства на основе сущностей 
Сущность (entity): Обособленно существующий предмет (материальный или нематериальный) [1.]. Описания сущностей PME, DCCE, DTRE, DTUE, CSE приведены в таблице 3 в соответствии с [2, с. 8-9] .

Таблица 3

Сущности структуры цифрового двойника производства

\begin{tabular}{|c|c|}
\hline $\begin{array}{l}\text { 1. Сущность } \\
\text { физического } \\
\text { производства (РМЕ) }\end{array}$ & $\begin{array}{l}\text { РМЕ именуют наблюдаемой производственной } \\
\text { сущностью в процессе производства, которая должна } \\
\text { отслеживаться и данные о состоянии которой должны } \\
\text { считываться, а также которая может приводиться в } \\
\text { действие и управляться DССЕ. РМЕ включает в себя } \\
\text { персонал, оборудование, материал и т.д. }\end{array}$ \\
\hline $\begin{array}{l}\text { 2. Сущность сбора } \\
\text { данных и управления } \\
\text { (DCCE) }\end{array}$ & $\begin{array}{l}\text { DCСЕ отслеживает, считывает данные о состоянии, } \\
\text { управляет, приводит в действие РМЕ и т. д. и, } \\
\text { следовательно, включает в себя датчики, исполнительные } \\
\text { устройства и контроллеры. } \\
\text { DCCE взаимодействует с сущностями представления } \\
\text { цифрового двойника (DTRE), т. е. OMSE, ASSE и RAISE, } \\
\text { для создания, синхронизации и управления цифровыми } \\
\text { двойниками, а именно цифровыми сущностями } \\
\text { наблюдаемых производственных элементов. }\end{array}$ \\
\hline $\begin{array}{l}\text { 3. Сущность } \\
\text { представления } \\
\text { цифрового двойника } \\
\text { (DTRE): }\end{array}$ & $\begin{array}{l}\text { Сущность представления цифрового двойника (DTRE) } \\
\text { подразделяется на виды (табл. 4): } \\
\text { Сущность подсистемы эксплуатации и управления } \\
\text { (OMSE); Сущность подсистемы приложений и сервисов } \\
\text { (ASSE); } \\
\text { Сущность подсистемы доступа к ресурсам и обмена } \\
\text { данными (RAISE) }\end{array}$ \\
\hline $\begin{array}{l}\text { 4. Сущность } \\
\text { пользователя } \\
\text { цифрового двойника } \\
\text { (DTUE) }\end{array}$ & $\begin{array}{l}\text { DTUE могут быть человек, устройство и система, } \\
\text { например MES, ERP и даже одноранговый DTRE. DTUE } \\
\text { должен обладать соответствующим интерфейсом, в } \\
\text { котором специфические возможности приложения } \\
\text { предоставляются базовым приложением, которое } \\
\text { взаимодействует с DTRE с помощью API, управляемым } \\
\text { RAISE. (рис. 3) }\end{array}$ \\
\hline $\begin{array}{l}\text { 5. Кросс-системная } \\
\text { сущность (CSE) }\end{array}$ & $\begin{array}{l}\text { CSE - сущность, которая находится в разных доменах, а } \\
\text { также входит в структуру цифрового двойника } \\
\text { производства для обеспечения общих функциональных } \\
\text { возможностей, таких как обмен данными, проверка } \\
\text { данных, обеспечение безопасности. }\end{array}$ \\
\hline
\end{tabular}


Сущность представления цифрового двойника (DTRE) предоставляет различные приложения и сервисы, включая эмуляцию производственной системы, анализ данных, полученных от РМЕ, отчетность о действиях, таких как производство и т д.

Комбинация сущностей OMSE, ASSE, RAISE является сущностью представления цифрового двойника DTRE, которая отображает в цифровом виде физические производственные ресурсы как цифровых двойников производства и поддерживает их работу. Описания сущностей OMSE, ASSE, RAISE приведены в таблице 4 в соответствии с [2, с. 9].

Таблица 4

Сущности подсистем представления цифрового двойника DTRE

\begin{tabular}{|l|l|}
\hline \multicolumn{1}{|c|}{ Сущность подсистемы } & \multicolumn{1}{|c|}{ Функции и задачи } \\
\hline $\begin{array}{l}\text { 1. Сущность подсистемы } \\
\text { уксплатации и }\end{array}$ & $\begin{array}{l}\text { OMSE использует и управляет DTRE. OMSE должна } \\
\text { сохранять данные о наблюдаемом производственном } \\
\text { элементе в процессе производства и проектирования, } \\
\text { включая цифровое моделирование, представление и } \\
\text { синхронизацию. }\end{array}$ \\
\hline $\begin{array}{l}\text { 2. Сущность подсистемы } \\
\text { приложений и сервисов } \\
\text { (ASSE) }\end{array}$ & $\begin{array}{l}\text { ASSE предоставляет функциональные возможности, } \\
\text { связанные с приложениями и сервисами, а также поддержку. }\end{array}$ \\
\hline $\begin{array}{l}\text { 3. Сущность подсистемы } \\
\text { доступа к ресурсам и } \\
\text { обмена данными } \\
\text { (RAISE) }\end{array}$ & $\begin{array}{l}\text { RAISE предоставляет доступ DTUE к функционалу DTRE с } \\
\text { управляемыми интерфейсами для приложений и сервисов, } \\
\text { функций администрирования и бизнес-функций для } \\
\text { обеспечения совместимости. }\end{array}$ \\
\hline
\end{tabular}

Комбинированная типовая модель цифрового двойника производства на основе доменов и сущностей представлена на рисунке 4. 


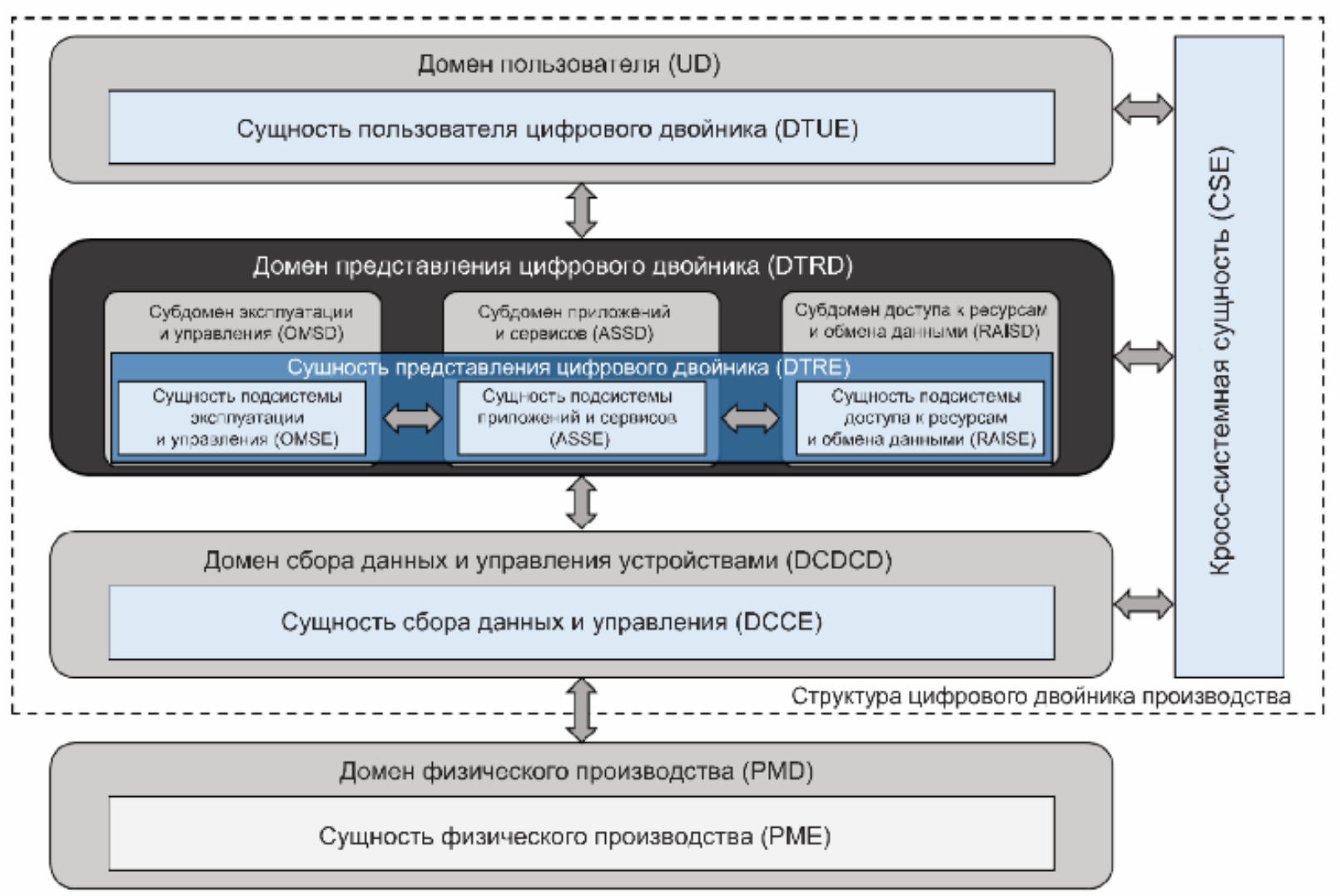

\section{Рис. 4. Комбинированная типовая модель цифрового двойника производства на основе доменов и сущностей}

Подсистема эксплуатации и управления OMSE, кроме указанной функции в таблице 4, также обеспечивает возможность использования и управления всего DTRE, например предоставление DTUE функций администрирования.

Функции управления доступом к ресурсам и обмена данными RAISE могут различаться в зависимости от типа DTUE, требующего аутентификации, авторизации и других необходимых действий.

В зависимости от сценариев использования домены и сущности могут быть расширены, объединены или добавлены в типовую модель.

\section{Выводы.}

1. Цифровой двойник умного производства представляет собой систему взаимосвязанных цифровых моделей изделия (продукта), технологических, производственных и эксплуатационных процессов, параметрами которых можно управлять полностью в виртуальной среде.

2. Технология цифровых двойников охватывает весь жизненный цикл изделия (продукта), включая этапы: НИР и ОКР, проектирования, производства, эксплуатации, обслуживания и утилизации. 
3. Применение технологии цифровых двойников для реализации проекта изделия позволяет обойтись производителя от проведения продолжительных и дорогостоящих натурных испытаний, а также быстро перепроектировать продукт под новые требования с минимизацией расчетных ошибок, связанных с человеческим фактором.

\section{Список литературы}

1. ПНСТ 429. Умное производство. Двойники цифровые производства. Часть 1. Общие положения. - М.: Стандартинформ, 2020. -12 с.

2. ПНСТ 430. Умное производство. Двойники цифровые производства. Часть 2. Типовая архитектура. - М.: Стандартинформ, 2020. -16 с.

3. ПНСТ 420 Информационные технологии. Интернет вещей промышленный. Типовая архитектура. - М.: Стандартинформ, 2020. -32 с.

() Андрианова Л.П., Голубев Д.М., 2021 